\title{
STEAM EDUCATION PARTNERSHIPS DURING COVID-19 HELP KEEP TEACHING FUN
}

\author{
Jeffrey A. Nowak Ph.D., Professor, Purdue University Fort Wayne, nowakj@pfw.edu
}

Carissa L. Lahrman, STEAM Resource Teacher, Fort Wayne CS, carissa.lahrman@fwcs.k12.in.us

\begin{abstract}
Since content standards were widely implemented, the pros and cons of community engagement on education have been studied from a variety of perspectives (Camasso \& Jagannathan, 2018; Minner \& Hiles, 2005; Parker et al., 2017). Pressure to adequately cover content standards has painted some educators into a corner. Since the start of 2020, an ongoing global pandemic, mask requirements, quarantines, and time-on-task assessments have been suffocating some educators. This research brief examines ways teachers within the Fort Wayne Community Schools (FWCS) remain optimistic.
\end{abstract}

\section{Partnerships Lead to Purposeful Hide and Seek Engagements}

Science, Technology, Engineering, Arts, and Mathematics (STEAM) educators within FWCS are finding their horizons broadened and mental health bettered via community partnerships between preK-12 schools, informal education centers, foundations, enterprise business, and higher education. This paper provides a synopsis of pros and cons learned while engaging in community partnerships with various institutions and organizations, including but not limited to: higher education institutions including Purdue University Fort Wayne, informal education centers such as Science Central, McMillen Health, and Boys \& Girls Clubs, afterschool programs including robotics and other competitions, peer preK-12 schools, foundations including the Makulinski Family Foundation, and business volunteers from BAE and AEP, among others. While COVID-19 has certainly placed a damper on certain forms of engagement, a short survey of FWCS STEAM teachers has indicated that a pandemic does not need to equate to a classroom lockdown. Community engagements during the COVID crisis have provided three "hide" and four "seek" tips FWCS teachers have used to help them enjoy and cherish their ongoing opportunity to educate youth.

Hide: 1. Fear of Rejection - This stifles and prevents opportunity.

2. Virtual/Online Fatigue - Cabin-fever is not good! Avoid doldrums.

3. COVID-19 Policies - May prevent classroom visits, but do not prevent online interactions.

Seek: 1. Look for ways to allow students to lead classroom learning.

2. See if Interactive Video Conferencing (IVC) may help. Many are grant-funded and free.

3. Call and request collaborations with area businesses and peer education organizations.

4. While social distancing rules may apply, go on virtual as well as physical field trips.

\section{Conclusion}

While COVID-19 has created many obstacles and imposed change upon how teachers conduct their classroom, this article has shared tips from STEAM educators within FWCS as to how they remain dynamic and positive with the help and assistance of community engagements and partnerships.

\section{References}

Camasso, M. J., \& Jagannathan, R. (2018). Nurture thru nature: Creating natural science identities in populations of disadvantaged children through community education partnership. The Journal of Environmental Education, 49(1), 30-42. https://doi.org/10.1080/00958964.2017.1357524

Minner, D. D., \& Hiles, E. (2005). Rural school-community partnerships: The case of science education. Issues in Teacher Education, 14(1), 81-94.

Parker, C., Kruchten, C., \& Moshfeghian, A. (2017). Connecting urban students with engineering design: Community-focused, student-driven projects. Afterschool Matters, 25, 38-44. 